\title{
First-principles study of an interfacial phase diagram in the V-doped WC-Co system
}

\author{
S. A. E. Johansson and G. Wahnström \\ Department of Applied Physics, Chalmers University of Technology, SE-412 96 Göteborg, Sweden
}

(Received 22 March 2012; revised manuscript received 10 June 2012; published 5 July 2012)

\begin{abstract}
We present a method of determining an interfacial phase diagram using density functional theory calculations for interface energetics. Cluster expansions based on these calculations are used in Monte Carlo simulations to obtain configurational free energies. The method is applied to study the segregation of V to the WC(0001)/Co interface and to construct the corresponding interface diagram, a "complexion" phase diagram. By CALPHADtype analysis for the adjoining bulk phases, a connection with real materials is made. We find that, in equilibrium, the interface contains a thin V-rich film for a wide range of temperatures and chemical potentials of $\mathrm{V}$ corresponding to $\mathrm{V}$ additions below the $(\mathrm{V}, \mathrm{W}) \mathrm{C}_{x}$ solubility limit. The results are compared with available experimental data, and implications of the strong segregation of $\mathrm{V}$ for the sintering process of $\mathrm{V}$-doped WC-Co are discussed.
\end{abstract}

DOI: 10.1103/PhysRevB.86.035403

PACS number(s): 05.70.Np, 68.35.Dv, 71.15.Nc

\section{INTRODUCTION}

For a polycrystalline material, the structure, composition, and energetics of its internal interfaces are decisive for the material's functional properties as well as its processing. The study of interfaces is hence of great importance and is a growing and rapidly advancing field within materials science. It has been well established that the appearance of certain interfacial "phases" different from those of the adjoining bulk phases (e.g., segregation structures, amorphous wetting films, etc.) can be understood from thermodynamic considerations, ${ }^{1-6}$ the disparate interfacial phases are equilibrium states stabilized by the interface. The term "complexion" has been suggested to separate these interfacial phases from ordinary bulk phases. ${ }^{7,8}$ The equilibrium complexion is determined by intensive thermodynamic variables as temperature $T$ and chemical potentials $\mu_{i}$, but also by the boundaries provided by the adjoining bulk phases.

In turn, the interface complexion can determine the rate of kinetic processes occurring in the interface. ${ }^{7-9}$ In some cases, kinetic rates associated with different interfacial complexions may span several orders of magnitude, exemplified by, e.g., activated sintering in several W-metal systems caused by premelting in grain boundaries, ${ }^{6,10}$ and changes in grain boundary mobility in doped alumina. ${ }^{7}$ Knowledge of how to control interfacial structure and thereby atomic transport rate is thus key for performing "interfacial kinetic engineering" as a means to tailor a microstructure for a specific application. To this end, interfacial phase diagrams indicating the complexion transition lines as function of thermodynamic variables are a valuable tool. .,7,11 $^{6}$

In this paper, we present theoretical modeling of an interface diagram in $T$ and $\mu_{i}$ for segregation structures in a ceramic-metal $\mathrm{WC} / \mathrm{Co}$ interface in a transition-metaldoped WC-Co system. Technologically, the WC-Co cemented carbides constitute an important class of composite materials well suited for applications where demands for hardness and wear resistance are high. The material is produced in a sintering process, in which carbide and metal powders densify into a microstructure of faceted WC grains embedded in a tough Co binder. Apart from varying the relative W, C, and Co contents, adding various transition metals also influences the material's microstructure. ${ }^{12,13}$ Much research has been aimed at producing cemented carbides with as small WC grain size as possible, down to the nanometer scale, as it has been speculated that such materials have excellent mechanical properties. ${ }^{14}$ It is well known that $\mathrm{V}$ additions to the WC-Co system effectively retard the growth of WC grains that takes place during sintering. ${ }^{15}$ It has been suggested that the growth inhibition is related to the formation of ultrathin V-rich films in the WC/Co interfaces, which would act as diffusion barriers for dissolving and/or reprecipitating $\mathrm{W}$ atoms thereby slowing down the kinetics of the WC growth process. ${ }^{16}$ However, the observed V-rich structure of the WC/Co interface in the final material does not necessarily correspond to the equilibrium state during sintering. ${ }^{17,18}$ The sintering process occurs at high temperature, including temperatures above the melting of the Co binder phase, where solubilities of $\mathrm{W}, \mathrm{C}$, and $\mathrm{V}$ in Co are high and where the interface region can be expected to be in a state of local chemical equilibrium. During cooling in the end of the sintering cycle, most of the dissolved atoms leave the Co binder phase $\mathrm{e}^{19}$ and reprecipitate onto existing WC grains. It is thus conceivable that experimentally observed atomic structures and $\mathrm{V}$ segregation correspond to a low-temperature equilibrium or some frozen-in state from the very end of the cooling. As most of the microstructural development occurs at high temperature, it is essential to know the equilibrium state of the WC/Co interface in a doped WC-Co system as a function of temperature and dopant addition. Only with this knowledge can a connection between WC growth kinetics and WC/Co interfacial structure and segregation eventually be established.

To predict the equilibrium state of an interface in an actual material, models of the free energy of both the interface region and the adjoining bulk phases are necessary. For the latter, thermodynamic modeling of the W-C-Co-M system (where $\mathrm{M}$ is an additional transition metal) through CALPHAD-type analysis has reached a rather mature level, ${ }^{20,21}$ and it is therefore appropriate to use these existing models where possible. However, formulating models for ceramic-metal interface energetics that take into account the effect of segregation based only on experimental input is likely not feasible. Interface energies are notoriously difficult to measure and the few available estimations (e.g., Ref. 22) for the carbide-Co systems 
stem from wetting experiments. Furthermore, as discussed above, chemical compositions measured in the ceramic-metal interface may be affected by the cooling process.

Instead, for the interface we propose an atomistic model based on density functional theory (DFT) calculations. For modeling of interfaces with complex bonding, DFT has proved its usefulness, ${ }^{23,24}$ and the WC/Co interface has been previously studied by us with same method. ${ }^{3,25-27}$ In this paper, our previous modeling is extended by also including configuration free energies into an interface model which we explicitly couple with thermodynamic modeling of the W-C-Co-M system. Configuration free energies at finite temperatures are obtained from Monte Carlo (MC) simulations with interactions based on the cluster expansion (CE) method. ${ }^{28-32}$ With CE coefficients fitted from an extensive set of DFT calculations, the CE provides an accurate approximation of the total energy for any given configuration of mixed atoms on a fixed lattice, yet at a small computational price.

In this paper, we apply our model to the basal $\mathrm{WC}(0001)$ surface, which is one of the most common WC boundary planes in sintered WC-Co. ${ }^{33}$ Although applicable for any transition-metal additive, we will in subsequent sections present and apply the model on the V-doped WC-Co system. Several experimental studies of $\mathrm{WC} / \mathrm{Co}$ and, in particular, $\mathrm{WC}(0001) / C o$ interfaces exist, ${ }^{16-18,34-44}$ allowing for comparison between model and experiment. In our previous DFT modeling, we found the interface energy between pure $\mathrm{VC}$ and Co to be lower than that between WC and Co. ${ }^{3,27}$ This energetic difference together with a good parametric fit between $\mathrm{VC}$ and $\mathrm{WC}$ is the underlying reason for the $\mathrm{V}$ segregation to $\mathrm{WC} / \mathrm{Co}$ interfaces. ${ }^{3,27}$ The current extended modeling allows us to calculate the $\mathrm{WC}(0001) / \mathrm{Co}$ interface diagram, the segregated amount of $\mathrm{V}$, and its effect on $\mathrm{WC}(0001) / \mathrm{Co}$ interface energy as function of temperature and chemical potential of $\mathrm{V}$.

The paper is organized as follows: In Sec. II, we introduce our interface model, and describe the coupling between DFT and thermodynamic modeling. The details of the DFT calculations of the WC/Co interface and CE construction are presented in Sec. III. Results are presented in Sec. IV, and the method is applied to a real material of known production parameters. Our predictions are discussed in connection with experimental results in Sec. V, where we also speculate on the mechanism of grain growth inhibition. Finally, the paper is summarized and concluded in Sec. VI.

\section{THERMODYNAMICS}

\section{A. Interface energy and segregation}

Generally, the propensity of an addition to segregate to an interface is governed by its effect on the interface energy $\gamma$. We write $\gamma$ as $^{45}$

$$
\gamma=\frac{1}{A}\left(G-\sum_{i} N_{i} \mu_{i}\right) .
$$

Here, $G$ is the Gibbs energy for the considered interface system, which contains a planar interface of area $A . N_{i}$ is the number of atoms in the system of component $i$ with a corresponding chemical potential $\mu_{i}$ determined by the reservoirs with which the interface is in equilibrium. The equilibrium interfacial state is given by the minimum of $\gamma$ under fixed $\mu_{i}$.

Next, we define an interface structural model for which an expression of $G$ can be formulated. To this end, we assume that the interface has a geometry of well-defined lattice sites, and that $\mathrm{V}$ and $\mathrm{W}$ atoms may mix in some of these sites. The $\mathrm{V}$ atoms are assumed to be contained within a thin (a few atomic layers) carbide structure in epitaxy with WC. As usual, ${ }^{21}$ the WC bulk phase is assumed to be perfectly stoichiometric with no solubility of other atoms, whereas the Co binder phase may contain dissolved $\mathrm{W}, \mathrm{V}$, and $\mathrm{C}$ atoms.

In analogy to the common way of modeling bulk phases in terms of formula units, we introduce a normalized quantity $g$ defined as the Gibbs energy of an interfacial unit of area $a \ll A$, and thus

$$
\frac{1}{a} g=\frac{1}{A} G
$$

On average, an interfacial unit contains $n_{i}=(a / A) N_{i}$ atoms of component $i$. The dimensions of the unit are determined by the periodicity of the interfacial lattice, so that each unit contains an integer $m$ mixed V-W lattice sites. Corresponding site fractions are denoted $y_{\mathrm{V}}$ and $y_{\mathrm{W}}$, respectively, and $y_{\mathrm{V}}+$ $y_{\mathrm{W}}=1$.

Several different atomic stackings $k$ in the interface are possible which, as will be shown, are stable under different thermodynamic conditions. For each stacking $k$, there is a corresponding Gibbs energy per interface unit $g^{k}$ and interface energy $\gamma^{k}=\frac{1}{a}\left(g^{k}-\sum_{i} n_{i} \mu_{i}\right)$. The stackings that we have used for the considered WC(0001)/Co interface system are described in detail and motivated in Sec. III B.

We now decompose $g^{k}$ into

$$
g^{k}=y_{\mathrm{V}} g_{\mathrm{WC} / \mathrm{VC} / \mathrm{Co}}^{k}+y_{\mathrm{W}} g_{\mathrm{WC} / \mathrm{WC} / \mathrm{Co}}^{k}+m g_{\mathrm{V}, \mathrm{W}}^{\operatorname{mix}, k}\left(y_{\mathrm{V}}, y_{\mathrm{W}}\right),
$$

where $g_{\mathrm{WC} / \mathrm{VC} / \mathrm{Co}}^{k}\left(g_{\mathrm{WC} / \mathrm{WC} / \mathrm{Co}}^{k}\right)$ corresponds to the Gibbs energy of an interface unit, in which the mixed sites are occupied entirely by $\mathrm{V}(\mathrm{W})$ atoms. The mixing free energy is denoted $g_{\mathrm{V}, \mathrm{W}}^{\operatorname{mix}, k}\left(y_{\mathrm{V}}, y_{\mathrm{W}}\right)$ and is, as usual, separated into an ideal and an excess part $g_{\mathrm{V}, \mathrm{W}}^{\mathrm{xs}, k}$, so that

$$
g_{\mathrm{V}, \mathrm{W}}^{\operatorname{mix}, k}\left(y_{\mathrm{V}}, y_{\mathrm{W}}\right)=k_{\mathrm{B}} T \sum_{i=\mathrm{V}, \mathrm{W}} y_{i} \ln y_{i}+g_{\mathrm{V}, \mathrm{W}}^{\mathrm{xs}, k}\left(y_{\mathrm{V}}, y_{\mathrm{W}}\right) .
$$

We now write

$$
\gamma^{k}=\frac{1}{a}\left(g^{k}\left(y_{\mathrm{V}}, y_{\mathrm{W}}\right)-m \sum_{i=\mathrm{V}, \mathrm{W}} y_{i} \mu_{i}-\sum_{i \notin \operatorname{mix}} n_{i} \mu_{i}\right) .
$$

The last quantity $\sum_{i \notin \operatorname{mix}} n_{i} \mu_{i}$ corresponds to the sum of chemical potentials of atoms that do not enter the mixed sites in our model, but nevertheless are part of the unit interface system. These include all $\mathrm{C}$ atoms, additional $\mathrm{W}$ atoms in the WC bulk region, and Co atoms of the binder phase.

Within the scheme above, the equilibrium interface energy $\gamma^{\text {eq }}$ and corresponding equilibrium structure and site fraction are given by the minimization

$$
\gamma^{\mathrm{eq}}=\min _{k} \min _{y_{\mathrm{V}}, y_{\mathrm{W}}} \gamma^{k}\left(y_{\mathrm{V}}, y_{\mathrm{W}}\right)
$$


To conclude this section, to find $\gamma^{\text {eq }}$, we need to calculate relevant differences between the free energy of the interface system and the chemical potentials $\sum_{i} n_{i} \mu_{i}$ of its constituents. In the next section, we will connect experimental conditions to suitable values for the potentials $\mu_{i}$.

\section{B. Chemical potentials}

We first consider the potentials of $\mathrm{W}$ and $\mathrm{C}, \mu_{\mathrm{W}}$ and $\mu_{\mathrm{C}}$. Since the interface system is in equilibrium with a stoichiometric WC bulk phase,

$$
\mu_{\mathrm{W}}+\mu_{\mathrm{C}}=g_{\text {shp WC }},
$$

where $g_{\text {shp WC }}$ is the Gibbs energy per formula unit of simple hexagonal WC. In the W-C-Co system, the WC + Co twophase field borders to the three-phase fields $\mathrm{WC}+\mathrm{Co}+$ graphite and $\mathrm{WC}+\mathrm{Co}+\eta$ for high and low $\mathrm{C}$ content, respectively ${ }^{21}$ [where $\eta$ is a $(\mathrm{Co}, \mathrm{W})_{6} \mathrm{C}$ carbide phase]. Within the two-phase field, it holds that

$$
\mu_{\mathrm{C}}=g_{\mathrm{gr}}-\Delta \mu_{\mathrm{C}},
$$

where $g_{\mathrm{gr}}$ is the Gibbs energy per atom of graphite and $0 \leqslant$ $\Delta \mu_{\mathrm{C}} \lesssim 0.25 \mathrm{eV}$ with the lower (upper) limit of $\Delta \mu_{\mathrm{C}}$ in the graphite $(\eta)$ limit. Combining Eqs. (7) and (8),

$$
\mu_{\mathrm{W}}=g_{\text {shp WC }}-g_{\mathrm{gr}}+\Delta \mu_{\mathrm{C}} .
$$

We now consider the potential $\mu_{\mathrm{V}}$ of the addition. The amount of $\mathrm{V}$ added to the WC-Co system will affect $\mu_{\mathrm{V}}$, and thereby the interface system. A maximum of $\mu_{\mathrm{V}}$ is attained when the addition of $\mathrm{V}$ is so large that a secondary carbide phase forms. For $\mathrm{V}$, this phase corresponds (at typical sintering temperatures and $\mathrm{C}$ contents) to a cubic $(\mathrm{V}, \mathrm{W}) \mathrm{C}_{x}$ substoichiometric $(x<1)$ carbide of $\mathrm{NaCl}$ structure. We relate $\mu_{\mathrm{V}}$ to a corresponding stoichiometric carbide $\mathrm{VC}$ and write

$$
\mu_{\mathrm{V}}+\mu_{\mathrm{C}}=g_{\mathrm{NaClVC}}-\Delta \mu_{\mathrm{VC}},
$$

from which

$$
\mu_{\mathrm{V}}=g_{\mathrm{NaClVC}}-g_{\mathrm{gr}}-\Delta \mu_{\mathrm{VC}}+\Delta \mu_{\mathrm{C}},
$$

where $g_{\mathrm{NaClVC}}$ is the Gibbs energy per formula unit of cubic VC. The quantity $\Delta \mu_{\mathrm{VC}}$ is a measure of how much $\mu_{\mathrm{V}}$ and/or $\mu_{\mathrm{C}}$ would have to be increased for stoichiometric VC precipitates to form. The minimum of $\Delta \mu_{\mathrm{VC}}$ corresponds to the formation of $(\mathrm{V}, \mathrm{W}) \mathrm{C}_{x}$, and due to the $\mathrm{V}-\mathrm{W}$ mixing and $\mathrm{C}$ vacancies in the $(\mathrm{V}, \mathrm{W}) \mathrm{C}_{x}$ phase, $\Delta \mu_{\mathrm{VC}}>0$.

Analogously for $\mathrm{Co}$,

$$
\mu_{\mathrm{Co}}=g_{\text {fcc Co }}-\Delta \mu_{\mathrm{Co}},
$$

where $g_{\mathrm{fcc} C o}$ is the Gibbs energy per formula unit of fcc Co. Assuming temperatures above the Co hcp-fcc transition, $\Delta \mu_{\mathrm{Co}}>0$ due to dissolved $\mathrm{W}, \mathrm{C}$, and $\mathrm{V}$ atoms in the Co phase. At yet higher temperatures, $\Delta \mu_{\mathrm{Co}}$ will increase further due to the liquid phase of Co having lower Gibbs energy than fcc Co.

Calculating chemical potentials with respect to chosen reference states is a standard procedure in thermodynamic software. For well-defined experimental conditions ( $T$ and composition), $\Delta \mu_{\mathrm{C}}, \Delta \mu_{\mathrm{VC}}$, and $\Delta \mu_{\mathrm{Co}}$ can thus be obtained given databases ${ }^{21,46}$ for the system at hand. An example is provided in Sec. IV C.

\section{Connecting DFT and thermodynamics}

We now seek to express $\gamma^{k}$ in a way amenable for calculation. With the chemical potentials $\mu_{i}$ rewritten according to Eqs. (8), (9), and (11), we are in a position to separate $\gamma^{k}$ into three parts: A $T$-independent part $\gamma_{0}^{k}$, a $T$-dependent part $\gamma_{T}^{k}$, and an environment-depending part $\gamma_{\text {env }}$, so that

$$
\gamma^{k}=\gamma_{0}^{k}+\gamma_{T}^{k}+\gamma_{\mathrm{env}},
$$

where

$$
\begin{aligned}
\gamma_{0}^{k}=\frac{1}{a}\left(g^{k}(0)-n_{\mathrm{W}}\left[g_{\mathrm{shp} \mathrm{WC}}(0)-g_{\mathrm{gr}}(0)\right]\right. & \\
- & \left.n_{\mathrm{V}}\left[g_{\mathrm{NaCl} \mathrm{VC}}(0)-g_{\mathrm{gr}}(0)\right]-n_{\mathrm{C}} g_{\mathrm{gr}}(0)-n_{\mathrm{Co}} g_{\mathrm{fcc} \mathrm{Co}}(0)\right) \\
\gamma_{T}^{k}= & \frac{1}{a}\left(g^{k}(T)-n_{\mathrm{W}}\left[g_{\mathrm{shp} \mathrm{WC}}(T)-g_{\mathrm{gr}}(T)\right]\right. \\
& -n_{\mathrm{V}}\left[g_{\mathrm{NaCl} \mathrm{VC}}(T)-g_{\mathrm{gr}}(T)\right]-n_{\mathrm{C}} g_{\mathrm{gr}}(T) \\
& \left.-n_{\mathrm{Co}} g_{\mathrm{fcc} \mathrm{Co}}(T)\right)-\gamma_{0}^{k},
\end{aligned}
$$

and

$$
\gamma_{\mathrm{env}}=\frac{1}{a}\left[\left(n_{\mathrm{C}}-n_{\mathrm{W}}-n_{\mathrm{V}}\right) \Delta \mu_{\mathrm{C}}+n_{\mathrm{V}} \Delta \mu_{\mathrm{VC}}+n_{\mathrm{Co}} \Delta \mu_{\mathrm{Co}}\right] .
$$

For the interface energetics at $T=0, \gamma_{0}^{k}$, we use straightforward DFT calculations ${ }^{47}$ to calculate the energy differences of Eq. (14) within the methodology presented in earlier papers. ${ }^{3,25-27}$ In the following, we will by $\gamma_{0}^{k}$ refer to the thermodynamic ground state of the interface at $T=0$, i.e., the lowest-energy configuration for given $n_{\mathrm{W}}, n_{\mathrm{V}}$, etc.

To approximate $\gamma_{T}^{k}$, we will for simplicity first analyze the energy of an interface system with $y_{\mathrm{V}}=0$ or $y_{\mathrm{V}}=1$, so that the mixing energy $g_{\mathrm{V}, \mathrm{W}}^{\mathrm{mix}, k}$, for the moment, can be disregarded. In this case, we approximate

$$
\gamma_{T}^{k} \approx 0 \text {. }
$$

A necessary condition for $\gamma_{T}^{k}=0$ to hold exactly is that the heat capacity of the interface system $-T \partial^{2} g^{k} / \partial T^{2}$ equals that of a combination of hexagonal WC, cubic VC, graphite, and fcc Co given by the $n_{i}$ of Eq. (15). In principle, any combination of reference phases (with well-defined lattice stabilities) could be used in Eqs. (8), (9), (11), (14), and (15); e.g., the pure metal bcc phases of $\mathrm{W}$ and $\mathrm{V}$, instead of hexagonal WC and cubic $\mathrm{VC}$, respectively. However, since the adjoining structures of the interface system are comprised of hexagonal WC and fcc $\mathrm{Co}$, and possibly a thin carbide film in-between, our choice of bulk phase references appearing in Eq. (15) is likely to be the best combination of bulk phases to approximate the heat capacity of the interface system. Although here on a very local level, setting $\gamma_{T}^{k}=0$ can be interpreted as an application of the empirical Neumann-Kopp law for estimating heat capacities of bulk phases. ${ }^{48}$

\section{Mixing energy}

We now turn to the case $0<y_{\mathrm{V}}<1$, where mixing is present. We use the same approximation as for the above nonmixing case, namely, that the heat capacity of the interface 
system is the same as for a combination of corresponding bulk phases but with an addition due to mixing, so that

$$
\gamma_{T}^{k}=\frac{m}{a}\left(g_{\mathrm{V}, \mathrm{W}}^{\operatorname{mix}, k}\left(T ; y_{\mathrm{V}}, y_{\mathrm{W}}\right)-g_{\mathrm{V}, \mathrm{W}}^{\operatorname{mix}, k}\left(0 ; y_{\mathrm{V}}, y_{\mathrm{W}}\right)\right) \text {. }
$$

The excess part of the mixing free energy $g_{\mathrm{V}, \mathrm{W}}^{\mathrm{xs}, k}$ is separated into its energetic $e_{\mathrm{V}, \mathrm{W}}^{\mathrm{xs}, k}$ and entropic $s_{\mathrm{V}, \mathrm{W}}^{\mathrm{xs}, k}$ parts:

$$
g_{\mathrm{V}, \mathrm{W}}^{\mathrm{xs}, k}=e_{\mathrm{V}, \mathrm{W}}^{\mathrm{xs}, k}-T s_{\mathrm{V}, \mathrm{W}}^{\mathrm{xs}, k}
$$

Both the excess total energy $e_{\mathrm{V}, \mathrm{W}}^{\mathrm{xs}, k}(T)$ and excess entropy $s_{\mathrm{V}, \mathrm{W}}^{\mathrm{xs}, k}(T)$ are obtained from MC simulations as described in Sec. III C. It should here be noted that in our modeling, the $T$ dependence in $g_{\mathrm{V}, \mathrm{W}}^{\mathrm{xs}, k}$ arises only due to the varying degree of $\mathrm{W}-\mathrm{V}$ ordering in the mixed lattice sites, as the $\mathrm{CE}$ coefficients we use in the MC simulations are $T$ independent in themselves.

\section{E. Temperature-dependent deviations and their consequences}

The most important deviations from the approximation used in Eqs. (17) and (18) and their physical origin are worth pointing out. The dominant contribution to the temperaturedependent part of a free energy, $g(T)-g(0)$, for a solid material is usually due to the vibrational motion of the atoms. In principle, the contribution to the free energy from atomic vibrations can be calculated in the (quasi)harmonic approximation from the phonon spectrum of the system. This can be acquired by first-principles methods as has been done, e.g., in Ref. 49 for stoichiometric transition-metal carbides and nitrides in their respective bulk phases. However, due to the large computational cost associated with vibrational computations, they were deemed intractable for the current project, especially considering the many atomic configurations needed to accurately map out the interface energetics and fit CEs. Usually, corrections due to vibrational free energy are considered small. ${ }^{50,51}$

More complex is the deviation that arises from the $T$-dependent magnetic structure of Co. From theoretical calculations, it is known that the magnetic state of Co influences its surface energy ${ }^{52}$ and metal-carbide interface energy (exemplified by TiC/Co in Ref. 53). The absolute value of a carbide/Co interface energy can change substantially $\left(\sim 0.4 \mathrm{~J} / \mathrm{m}^{2}\right)$ when treating $\mathrm{Co}$ as either ferromagnetic or nonmagnetic, ${ }^{27,53}$ although the relative differences between various carbide/Co interfaces do not. ${ }^{27}$ The influence of the magnetic state of $\mathrm{Co}$ will be further discussed in Sec. V B.

Another complication is posed by the two phases (fcc and liquid) of Co that appear in the temperature interval relevant for sintering. In phenomenological descriptions of interface energy (see, e.g., Ref. 54), solid/liquid interface energies are sometimes considered as stemming from two parts: a chemical energy due to the differing atomic bonds across the interface, and a structural energy due to the disturbance of the liquid's structure caused by the interface. Of course, we can only assess the first part by static DFT calculations. However, the latter part should not depend on the concentration of segregated atoms in the segregation layers, as the planar geometry of the
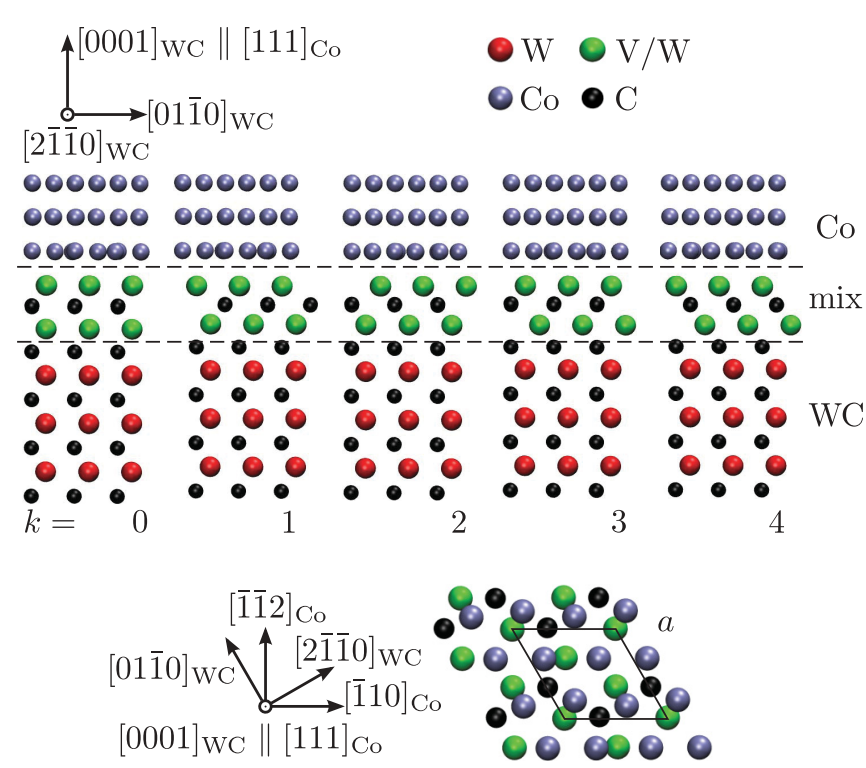

FIG. 1. (Color online) An illustration of atomic setups $k$ in the interface viewed from (upper plot) the side along [2 $\overline{1} \overline{1} 0]_{\mathrm{WC}}$, and (lower plot) the top along [0001 $]_{\mathrm{WC}}$. In the view along $[0001]_{\mathrm{WC}}$, the atomic setups $k$ appear identical in the layer closest to the interface (except small variations in atomic relaxation). The dimensions within the interface plane of the smallest supercell of interfacial area $a$ used in the calculations are outlined in the lower plot. In both plots, atomic positions are relaxed.

outermost interface layer in the carbide remains unchanged (see Sec. III B and Fig. 1).

To conclude the discussion above, the absolute value of the WC/Co interface energy calculated in the scheme presented in the preceding sections will not be accurate at high temperature. However, both the effect of Co magnetism and the liquid phase of Co should to large degree cancel when considering a difference $\gamma^{k_{2}}\left(y_{\mathrm{V}_{2}}, y_{\mathrm{W}_{2}}\right)-\gamma^{k_{1}}\left(y_{\mathrm{V}_{1}}, y_{\mathrm{W}_{1}}\right)$ between interfaces of different atomic setups and site fractions calculated at the same thermodynamic conditions $T$ and $\mu_{i}$. Therefore, in the following, we will mainly present our results as relative interface energies

$$
\Delta \gamma^{k}\left(y_{\mathrm{V}}, y_{\mathrm{W}}\right)=\gamma^{k}\left(y_{\mathrm{V}}, y_{\mathrm{W}}\right)-\gamma^{k=0}(0,1),
$$

i.e., the difference in energy between an interface $k$ containing $\mathrm{V}$ at site fraction $y_{\mathrm{V}}$ and the unreconstructed $(k=0$, see Sec. III B) interface containing no V. Strictly speaking, this means that we are calculating free-energy differences between systems containing an interface rather than the actual interface energy. A corresponding $T=0$ quantity $\Delta \gamma_{0}$ is defined analogously with Eq. (20) using $\gamma_{0}$ of Eq. (14).

In our model system, we do not consider the mixing of Co atoms into the interfacial segregation carbide structure. Neither do we consider $\mathrm{W}$ or $\mathrm{V}$ segregation on the binder phase side of the sharp WC/Co interface. Consequently, $n_{\mathrm{Co}}$ remains constant in all simulations, and the term $n_{\mathrm{Co}} \Delta \mu_{\mathrm{Co}}$ of Eq. (16) will therefore cancel in $\Delta \gamma^{k}$ of Eq. (20). A realistic value of $\Delta \mu_{\mathrm{Co}}$ is hence of little importance for the current simulations, and, in the following, where an absolute value of $\gamma$ is given, we have set $\Delta \mu_{\mathrm{Co}}=0$. 


\section{MODELING THE WC/CO INTERFACE}

\section{A. DFT computational details}

All DFT calculations have been performed using the Vienna $a b$ initio simulation package (VASP). ${ }^{47}$ For the exchangecorrelation effects, we employ the generalized gradient approximation (GGA). Its use for the considered interface systems has been motivated in Ref. 55. The exchange-correlation functional is approximated in the Perdew-Burke-Ernzerhof (PBE) scheme. ${ }^{56}$ A plane-wave implementation with projector augmented wave (PAW) potentials is used. ${ }^{57,58}$ The plane-wave energy cutoff is set to $400 \mathrm{eV}$ in all calculations. Partial occupancies are set with the method of Methfessel-Paxton ${ }^{59}$ of first order with a smearing parameter of $0.1 \mathrm{eV}$. Atomic relaxations are performed until all atomic forces are smaller than $0.03 \mathrm{eV} / \AA$. $k$-point sampling is done with $\Gamma$-centered grids dense enough to converge all interface energies to a total computational error within $0.03 \mathrm{~J} / \mathrm{m}^{2}$. Where possible, $k$-point sampling is done consistently between interface and bulk systems.

\section{B. Structural models}

It is well known from high-resolution transmission electron microscope (HRTEM) imaging that the atomic structure of the WC(0001) surface in contact with Co deviates from that of bulk WC, ${ }^{16,17,34-40,60-62}$ especially when the WC-Co system is doped with $\mathrm{Ti}, \mathrm{V}$, or Cr. In Refs. 16 and 37, it was deduced that the segregation structure can be described as an ultrathin $(\mathrm{V}, \mathrm{W}) \mathrm{C}$ film of cubic structure with a relationship $(0001)_{\mathrm{WC}} \|$ $(111)_{(\mathrm{V}, \mathrm{W}) \mathrm{C}}$ between the WC grain and the $(\mathrm{V}, \mathrm{W}) \mathrm{C}$ film. In the $[0001]_{\mathrm{WC}}$ and $[111]_{(\mathrm{V}, \mathrm{W}) \mathrm{C}}$ directions, respectively, both $\mathrm{WC}$ and $(\mathrm{V}, \mathrm{W}) \mathrm{C}$ consist of alternating layers of metal and $\mathrm{C}$ atoms. As a function of the number of $\mathrm{V}$ layers in the segregation structure, the total interface energy converges to a sum of WC/VC and VC/Co interface energies within just two V layers. ${ }^{3,27}$ For conditions where the bulk (V,W)C phase itself is thermodynamically unstable, this means that the maximal thickness of an equilibrium segregation structure should be limited to two metal atom layers and, therefore, we may restrict our modeling to include only such ultrathin structures.

In Fig. 1, the modeled atomic structures are depicted. Assigning positions $A$ to $(0,0), B$ to $\left(\frac{1}{3}, \frac{2}{3}\right)$, and $C$ to $\left(\frac{2}{3}, \frac{1}{3}\right)$ with respect to hexagonal lattice vectors in the $(0001)_{\mathrm{WC}}$ plane, the bulk WC stacking sequence along [0001] $]_{\mathrm{WC}}$ is $\ldots \mathrm{W}_{A} \mathrm{C}_{B} \mathrm{~W}_{A} \mathrm{C}_{B} \ldots$ The setup $k=0$ corresponds simply to a ... W $\mathrm{W}_{A} \mathrm{C}_{B} \mathrm{~W}_{A}$ stacking at the surface. To continue building (111) layers of cubic carbide onto the $\mathrm{WC}(0001)$ surface, we consider the sequence $\ldots \mathrm{W}_{A} \mathrm{C}_{B} \mathrm{~W}_{A} \mathrm{C}_{B}$ and stack the next metal atom (111) layer in the $A$ or $C$ sites, as only these stackings are associated with low energy. ${ }^{3}$ Given these starting sites, the setups $1 \leqslant k \leqslant 4$ include all possible stackings with two metal atom layers of cubic carbide.

We also restrict the atomic models to include only two layers of mixed sites. This is motivated by the low solubility of $\mathrm{V}$ in WC in a typical V-doped WC-Co (around $2 \times 10^{-3}$ of the metal atoms ${ }^{63}$ ). The impact on interfacial segregation due to dissolved $\mathrm{V}$ in the bulk of $\mathrm{WC}$ is therefore negligible, and any noticeable segregation of $\mathrm{V}$ must be restricted to the very surface layers of WC. Furthermore, we have not mapped out the energetics of $\mathrm{C}$ vacancies in combination with mixing of metal atoms (effectively a $2 \times 2$-component system with $\mathrm{C}$ vacancy and $\mathrm{W}-\mathrm{V}$ mixing). Apart from the carbide surface termination (see below), we model the segregation layers as perfectly stoichiometric (no $\mathrm{C}$ vacancies). The effect of this is discussed in Sec. V B.

We now turn to the carbide/Co interface. Due to the many calculations needed to fit the CEs, it is for computational reasons preferable to use as small a supercell as possible, yet still keep the strain needed to create a commensurate carbide/Co interface minimal to retain a realistic atomic density in the interface. We choose to use a $(0001)_{\mathrm{WC}} \|(111)_{\mathrm{Co}}$ orientation with a $30^{\circ}$ angle between $[2 \overline{1} \overline{1} 0]_{\mathrm{WC}}$ and $[\overline{1} 10]_{\mathrm{Co}}$, which gives a supercell (see Fig. 1) with a planar density of 4 Co atoms per $3 \mathrm{M}$ atoms, and $m=6$ mixed sites. With calculated lattice parameters of $a_{\mathrm{WC}}=2.915 \AA$ and $a_{\mathrm{Co}}=3.519 \AA$ (spinpolarized Co), we introduce a strain $\epsilon_{[\overline{1} 10]_{\mathrm{Co}}}=\epsilon_{[\overline{1} \overline{1} 2]_{\mathrm{Co}}}=1.5 \%$ exclusively in the Co phase to account for the remaining WC/Co misfit. This gives a corresponding small elastic energy of $6 \mathrm{meV}$ per Co atom, a Poisson strain $\epsilon_{[111]_{\mathrm{Co}}}=-0.9 \%$, and a negligible change in the bulk Co electronic structure. A corresponding elastic energy is subtracted when calculating $\gamma$.

The studied $(0001)_{\mathrm{WC}} \|(111)_{\mathrm{Co}}$ orientation is typical for $\mathrm{WC}(0001) / C o$ interfaces in solid-state sintered WC-Co (Ref. 62) and exists also in liquid-phase sintered WC-Co (after cooling). ${ }^{64}$ It is thus a realistic interface geometry, although our particular choice of rotation state of Co with respect to the $(0001)_{\mathrm{WC}} \|(111)_{\mathrm{Co}}$ interface normal was not found in the TEM study of Ref. 64 (there denoted OR2). In an earlier study, ${ }^{65}$ we found that calculated $\mathrm{WC}(0001) / \mathrm{Co}$ interface energies for (111) and (001) Co surfaces are similar. It is therefore plausible to presume that predictions for the present $\mathrm{WC}(0001) / \mathrm{Co}(111)$ interface hold also for interfaces between WC(0001) and other low-index Co surfaces.

Because of the layered structure of $\mathrm{WC}$ and $(\mathrm{V}, \mathrm{W}) \mathrm{C}$ along $[0001]_{\mathrm{WC}} \|[111]_{(\mathrm{V}, \mathrm{W}) \mathrm{C}}$, the carbide/Co interface can either be metal- or C-terminated. By comparing $\gamma_{0}$ of completely metal- or C-terminated carbide slabs, we find that $\gamma_{0}$ of C-terminated interfaces are in all tested cases (which include all setups $k$ with $y_{\mathrm{V}}=0$ or 1 ) higher than for corresponding metal-terminated interfaces; at least $0.45 \mathrm{eV}$ per interfacial $\mathrm{W} / \mathrm{V}$ atom $\left(0.98 \mathrm{~J} / \mathrm{m}^{2}\right)$. This difference would increase further if adding the environmental term $\gamma_{\text {env }}$ to reflect the effect of a lower $\mathrm{C}$ potential $\left[\Delta \mu_{\mathrm{C}} \geqslant 0\right.$ in Eq. (8)]. However, this does not rule out the possibility of low-energetic partially C-terminated interface configurations. In Ref. 65, we studied such termination configurations in a $\mathrm{WC}(0001) / \mathrm{Co}(111)$ interface of a different Co orientation state $\left([2 \overline{1} \overline{1} 0]_{\mathrm{WC}} \|\left[{ }_{1} 10\right]_{\mathrm{Co}}\right.$ denoted OR1 in Ref. 64), which yields a special semicoherent WC/Co interface. For that orientation, partially C-terminated configurations with lower energy than the completely $\mathrm{W}$ terminated interface do exist and are associated with regions of the interface being either $\mathrm{W}$ - or C-terminated. ${ }^{65}$ Such atomic setups can, however, not occur in the present incoherent interface, which we expect to better represent a general WC(0001)/Co interface. Therefore, in all calculations used for fitting the CEs, we have assumed the carbide surface to be metal-terminated.

The variation of $\gamma_{0}$ as function of Co translation state with respect to the underlying metal-terminated carbide is 
small; max and min points on the $\gamma$ surface $^{45}$ differ by maximally $0.07 \mathrm{eV}$ per interfacial $\mathrm{V} / \mathrm{W}$ atom $\left(0.15 \mathrm{~J} / \mathrm{m}^{2}\right)$ and this difference varies little $(\sim 0.01 \mathrm{eV})$ between different setups $k$ and terminations $(\mathrm{V} / \mathrm{W})$. In cases where a unique minimum of $\gamma_{0}$ as function of Co translation state can be found, it corresponds to a configuration where one Co atom resides over a $\mathrm{C}$ atom and three $\mathrm{Co}$ atoms reside midway between $\mathrm{C}$ atoms as shown in Fig. 1. This is the translation state we choose for fitting the CEs.

It can be noted that in our previous studies of the $\mathrm{WC} / \mathrm{Co}$ interface, ${ }^{3,25-27}$ we used a Co phase strained to coherence with WC and calculated the interface energy as a mean value over several Co translations to simulate an incoherent interface. The current modeling includes only two symmetrically inequivalent positions of Co with respect to the underlying carbide (see Fig. 1), but it nevertheless captures an essential property of the interface energetics of an incoherent interface: the small variation of $\gamma$ with interphase translation.

\section{CE and MC}

The interface structures $k$ of Fig. 1 are used as input to the ATAT package, ${ }^{29-32}$ which using VASP calculates energies for different V-W configurations and thereafter constructs the CEs. To limit the computational effort, we use non-spin-polarized calculations for fitting the CEs.

To find $e_{\mathrm{V}, \mathrm{W}}^{\mathrm{xs}, k}(T)$ and $s_{\mathrm{V}, \mathrm{W}}^{\mathrm{xs}, k}(T)$, MC simulations in the canonical ensemble are performed. We obtain $e_{\mathrm{V}, \mathrm{W}}^{\mathrm{xs}, k}$ as

$$
e_{\mathrm{V}, \mathrm{W}}^{\mathrm{xs}, k}\left(T ; y_{\mathrm{V}}, y_{\mathrm{W}}\right)=\operatorname{Mean}\left[e_{\mathrm{MC}}\left(T ; y_{\mathrm{V}}, y_{\mathrm{W}}\right)\right],
$$

and $s_{\mathrm{V}, \mathrm{W}}^{\mathrm{xs}, k}$ by thermodynamic integration in $T$, so that

$$
\begin{aligned}
& s_{\mathrm{V}, \mathrm{W}}^{\mathrm{xs}, k}\left(T ; y_{\mathrm{M}}, y_{\mathrm{W}}\right) \\
& \quad=-k_{\mathrm{B}} M \int_{0}^{\frac{1}{k_{\mathrm{B}} T}} \beta \operatorname{Var}\left[e_{\mathrm{MC}}\left(\frac{1}{k_{\mathrm{B}} \beta} ; y_{\mathrm{V}}, y_{\mathrm{W}}\right)\right] d \beta .
\end{aligned}
$$

Here, $e_{\mathrm{MC}}$ is the total energy per site in the MC simulation, $\beta$ is an integration variable related to temperature through $\beta=1 /\left(k_{\mathrm{B}} T\right)$, and Mean $(\ldots)[\operatorname{Var}(\ldots)]$ is the mean (variance) of $e_{\mathrm{MC}}$. Since we are interested in the high-temperature properties of the interface, we avoid mapping out lowtemperature ordered states (and corresponding order-disorder transformations) by integrating from the disordered state at $T=\infty$ in Eq. (22). Simulations are run at different temperatures and concentrations varying $1 / T$ in steps of maximally $5 \times 10^{-5} \mathrm{~K}^{-1}$ and $y_{\mathrm{V}}$ in steps of 0.05 . The sampled $e_{\mathrm{V}, \mathrm{W}}^{\mathrm{xs}, k}$ and $s_{\mathrm{V}, \mathrm{W}}^{\mathrm{xs}, k}$ are connected by splines for use in Eqs. (3) through (6).

\section{RESULTS}

\section{A. Interfacial structure and energetics}

For each $k$, around $30 \mathrm{~V}-\mathrm{W}$ configurations generated by ATAT were found necessary to produce accurate CEs. Calculated excess total energies from DFT and the CE fit are given in Fig. 2 together with the DFT ground-state line connecting the lowest-energy configurations thus marking $e_{\mathrm{V}, \mathrm{W}}^{\mathrm{xs}}(T=0)$. The CE fit is worst for $k=1$ with a cross-validation score ${ }^{31}$ of $7 \mathrm{meV} /$ site and a rms error of $4 \mathrm{meV} / \mathrm{site}$, whereas the other

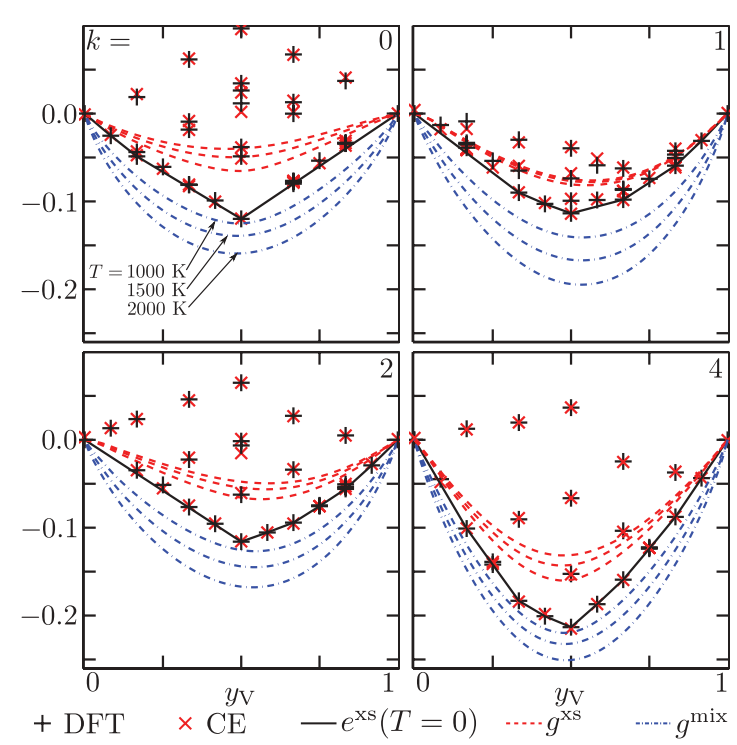

FIG. 2. (Color online) Excess total energies (in eV/site) from DFT and corresponding $\mathrm{CE}$ fit for different atomic configurations. The solid line corresponds to $e_{\mathrm{V}, \mathrm{W}}^{\mathrm{xs}}(T=0)$. The dashed and slash-dotted lines correspond to $g_{\mathrm{V}, \mathrm{W}}^{\mathrm{xS}}$ and $g_{\mathrm{V}, \mathrm{W}}^{\mathrm{mix}}$, respectively, at three different $T$ from MC simulations. $g_{\mathrm{V}, \mathrm{W}}^{\mathrm{xs}}$ increases and $g_{\mathrm{V}, \mathrm{W}}^{\mathrm{mix}}$ decreases as $T$ increases.

$k$ have errors around half of these values. Thus, we conclude that $\mathrm{CE}$ errors are within the typical accuracy of the DFT calculations.

For the MC simulations, a cell periodic in the interface plane consisting of $M=1176$ sites was found large enough to converge mean and standard deviation of $e_{\mathrm{MC}}$ within $10^{-5} \mathrm{eV}$ with respect to $M$ in the studied temperature interval. $g_{\mathrm{V}, \mathrm{W}}^{\mathrm{xs}}$ and $g_{\mathrm{V}, \mathrm{W}}^{\text {mix }}$ obtained from Eqs. (21) and (22) for a few different $T$ are presented in Fig. 2.

With $g_{\mathrm{V}, \mathrm{W}}^{\mathrm{mix}}$ determined, the remaining quantities to be added to the Gibbs energies $g^{k}$ of Eq. (3) are $y_{\mathrm{V}} g_{\mathrm{WC} / \mathrm{VC} / \mathrm{Co}}^{k}$ and $y_{\mathrm{W}} g_{\mathrm{WC} / \mathrm{WC} / \mathrm{Co}}^{k}$. In Fig. 3, the resulting $\Delta \gamma^{k}$ of Eq. (20) are plotted. Also, results for individual atomic configurations are included to allow for comparison with Fig. 2. For simplicity, we have set all $\Delta \mu=0$ and thus $\gamma_{\text {env }}=0$ corresponding to a $\mathrm{V}$ and $\mathrm{C}$-rich environment. Under these conditions, the energetic effect of introducing $\mathrm{V}$ in the WC/Co interface is substantial and all $\Delta \gamma^{k}<0$ at large $y_{\mathrm{V}}$ for $1 \leqslant k \leqslant 4$. The setup $k=3$ has been omitted in both Figs. 2 and 3 as $\gamma^{k=3}\left(y_{\mathrm{V}}\right)$ for no value of $y_{\mathrm{V}}$ is a minimum or close to minimum among the setups $k$.

Since we use two mixed layers in the model systems, $y_{\mathrm{V}}=$ $\frac{1}{2}$ corresponds to one equivalent (111) monolayer of $\mathrm{V}$ in VC. The clear minima in excess energy $e_{\mathrm{V}, \mathrm{W}}^{\mathrm{xs}, k}$ at $y_{\mathrm{V}}=\frac{1}{2}$ as seen in Fig. 2 do for all $k$ correspond to one atomic layer being filled completely with $\mathrm{V}$ atoms. For $k=0$ and 2, the stacking of $\mathrm{C}$ atoms surrounding the second and third metal atom layers in the carbide matches that of hexagonal WC, and as could be expected from the low solubility of $\mathrm{V}$ in hexagonal $\mathrm{WC}$, a minimum in $e_{\mathrm{V}, \mathrm{W}}^{\mathrm{xs}, k}$ is found when $\mathrm{V}$ atoms fill the interface layer. For $k=1$ and 4 , the atomic stacking of $\mathrm{C}$ atoms surrounding the second metal atom layer instead matches that of cubic $\mathrm{VC}$, and the minimum in $e_{\mathrm{V}, \mathrm{W}}^{\mathrm{xs}, k}$ corresponds to the second layer being filled with $\mathrm{V}$ atoms. For fractions $y_{\mathrm{V}}<\frac{1}{2}$, the low-energy 


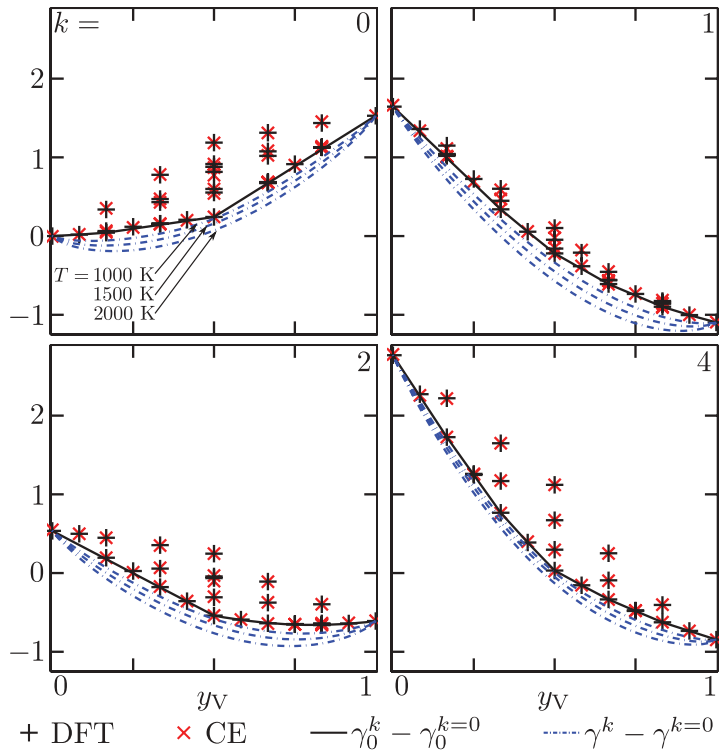

FIG. 3. (Color online) Relative interface energies $\left(\mathrm{J} / \mathrm{m}^{2}\right)$ at $T=0$ [ $\Delta \gamma_{0}^{k}\left(y_{\mathrm{V}}\right)$, solid line $]$ and $T>0\left[\Delta \gamma^{k}\left(y_{\mathrm{V}}\right)\right.$, dashed-dotted line $]$ under $\gamma_{\mathrm{env}}=0$.

configurations generally correspond to partial filling of the preferred layer, and for $y_{\mathrm{V}}>\frac{1}{2}$, complete and partial filling of the preferred and nonpreferred layers, respectively. For $k=$ 3 , the $\mathrm{C}$ stacking surrounding the second metal atom layer matches that of WC, but the second layer itself is displaced compared to the bulk WC, thereby possibly explaining why $k=3$ is not a minimum for any $y_{\mathrm{V}}$. For this setup, $\mathrm{V}$ atoms prefer the surface layer.

\section{B. Interfacial phase diagram}

Using our calculated relative interface energies, we can now map out the $\mathrm{WC}(0001) / \mathrm{Co}$ interface diagram as a function of $\Delta \mu_{\mathrm{VC}}$ and $T$, which we present in Fig. 4. First of all, the $(\mathrm{V}, \mathrm{W}) \mathrm{C}_{x}$ stability line limits the $\Delta \mu_{\mathrm{VC}}-T$ region for which our interface model is applicable. When approaching the $(\mathrm{V}, \mathrm{W}) \mathrm{C}_{x}$ stability line, the $(\mathrm{V}, \mathrm{W}) \mathrm{C}_{x}$ phase could nucleate on the WC(0001) surface, and the size and thickness of such precipitates would not directly depend on thermodynamic parameters. It should be noted that the exact location of the $(\mathrm{V}, \mathrm{W}) \mathrm{C}_{x}$ stability line in the $\Delta \mu_{\mathrm{VC}}-T$ diagram depends on the $\mathrm{C}$ potential $\mu_{\mathrm{C}}$, and one example is drawn in Fig. 4 (see Sec. IV C).

For relevant $\Delta \mu_{\mathrm{VC}}$ and $T$, three different regions exist in the $\Delta \mu_{\mathrm{VC}}-T$ diagram. For low $\Delta \mu_{\mathrm{VC}}$, the setup $k=1$ is associated with the lowest free energy. The mixed layers are $\mathrm{V}$ rich with $y_{\mathrm{V}}$ ranging from 0.96 to 0.74 in the depicted region. Appearing only as a thin wedge in Fig. 4 , the $k=2$ region expands at higher $T$ and is associated with a lower $\mathrm{V}$ content than $k=1$; $y_{\mathrm{V}}$ is around 0.48 . At around $\Delta \mu_{\mathrm{VC}}=0.3 \mathrm{eV}$, the $k=0$ region appears, which has a lower $\mathrm{V}$ content of, at its limits, $y_{\mathrm{V}}=0.01$ and 0.05 at $T=1000$ and $2000 \mathrm{~K}$, respectively. Thus, with two mixed interface layers, the three different stackings are well separated in terms of total V content; 1.5 to $1.9(k=1), 1.0$ $(k=2)$, or less than $0.1(k=0)$ equivalent $\mathrm{V}$ monolayers.

Also the relative interface energy is plotted in Fig. 4. At low $\Delta \mu_{\mathrm{VC}}, \mathrm{V}$ segregation decreases the WC/Co interface energy

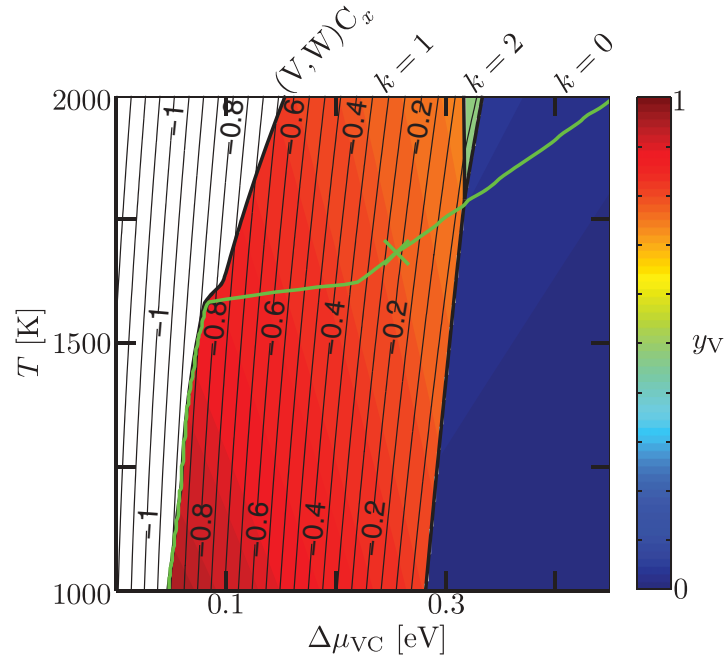

FIG. 4. (Color online) The calculated WC(0001)/Co interfacial phase diagram in V-doped WC-Co. The (thin) black contours correspond to the relative interface energy $\Delta \gamma\left(\mathrm{J} / \mathrm{m}^{2}\right)$ and are separated by $0.05 \mathrm{~J} / \mathrm{m}^{2}$. The green line corresponds to the $\Delta \mu_{\mathrm{VC}}-T$ curve in one example of V-doped WC-Co. The maximal sintering temperature is marked by the green cross. The black lines mark the interfacial transitions. The leftmost black line corresponds to the stability of the $(\mathrm{V}, \mathrm{W}) \mathrm{C}_{x}$ phase assuming the same $\mathrm{C}$ potential $\mu_{\mathrm{C}}$ as in the example material. The color within the regions $k=0,1$, and 2 , respectively, shows the equilibrium site fraction $y_{\mathrm{V}}$.

by maximally around $1.1 \mathrm{~J} / \mathrm{m}^{2}$. At the border to the low segregation state, the effect is only around $0.05 \mathrm{~J} / \mathrm{m}^{2}$ and decreases further as $\Delta \mu_{\mathrm{VC}}$ increases.

\section{An example material}

In this section, we use the calculated interface diagram of Fig. 4 to make predictions for a real V-doped WC-Co material, which was produced and investigated by Weidow et al. ${ }^{12,42}$ The composition of the material is given in Table I and details regarding its manufacture can be found in Ref. 12. The V addition used is rather typical for WC grain growth inhibition, and a significantly smaller WC grain size was reported for this material compared with a reference straight WC-Co. ${ }^{12}$

Using the THERMOCALC software ${ }^{66}$ with appropriate databases, ${ }^{21,46}$ the material's $\Delta \mu_{\mathrm{VC}}-T$ curve was calculated and is superposed on the interface diagram of Fig. 4. In Fig. 5, we have plotted the layer-dependent site fractions $y_{\mathrm{V}, 1}$ and $y_{\mathrm{V}, 2}$, where $y_{\mathrm{V}, 1}\left(y_{\mathrm{V}, 2}\right)$ is the fraction of $\mathrm{V}$ in the metal atom layer of the carbide closest to $\mathrm{Co}$ (second metal atom layer). The total $\mathrm{V}$ content $y_{\mathrm{V}, 1}+y_{\mathrm{V}, 2}=2 y_{\mathrm{V}}$ is also plotted as well as $\Delta \gamma$ as function of $T$.

For this material, the $(\mathrm{V}, \mathrm{W}) \mathrm{C}_{x}$ bulk phase is stable at low temperatures up to around $1550 \mathrm{~K}$, above which it should be completely dissolved into the binder. Accordingly, the

TABLE I. The composition in at.\% of the as-sintered example material.

\begin{tabular}{lccc}
\hline \hline $\mathrm{W}$ & $\mathrm{C}$ & $\mathrm{Co}$ & $\mathrm{V}$ \\
\hline 0.4215 & 0.4167 & 0.1564 & 0.0054 \\
\hline \hline
\end{tabular}




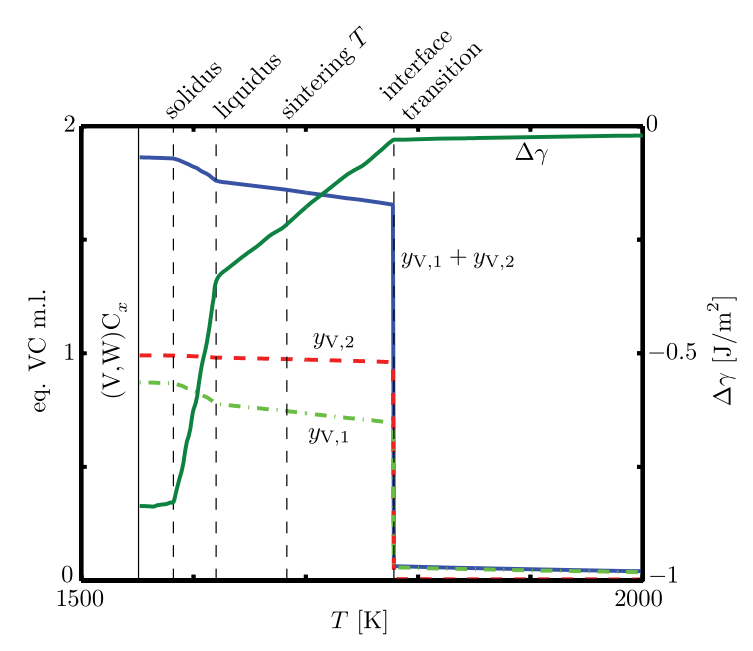

FIG. 5. (Color online) Layer-dependent site fractions $y_{\mathrm{V}, 1}$ and $y_{\mathrm{V}, 2}$ and total $\mathrm{V}$ content $y_{\mathrm{V}, 1}+y_{\mathrm{V}, 2}$ in terms of equivalent $\mathrm{V}$ monolayers (left axis) and relative interface energy $\Delta \gamma$ (right axis) for the $\mathrm{WC}(0001) / C$ interface in one example of V-doped WC-Co. $y_{\mathrm{V}, 1}\left(y_{\mathrm{V}, 2}\right)$ is the site fraction of $\mathrm{V}$ in the metal atom layer of the carbide closest to Co (second metal atom layer).

$\Delta \mu_{\mathrm{VC}}-T$ curve follows the $(\mathrm{V}, \mathrm{W}) \mathrm{C}_{x}$ stability line for low temperatures. The first two kinks of the curves in Figs. 4 and 5 appear at the binder solidus and liquidus temperatures, respectively. Within the solidus-liquidus region, $\Delta \mu_{\mathrm{VC}}$ increases sharply due to the larger $\mathrm{V}$ solubility in liquid Co than in fcc $\mathrm{Co}$, and correspondingly the effect of $\mathrm{V}$ on the interface energy decreases. The holding temperature during liquidphase sintering is $1683 \mathrm{~K}$. According to the calculated interface diagram, this means that the $\mathrm{WC}(0001) / C o$ interfaces are in the high-segregation state $(k=1)$ throughout the liquid-phase sintering stage, but would have crossed the interfacial phase transition line to the low-segregation state $(k=0)$ if heated above $1780 \mathrm{~K}$. Figure 5 also shows that in the high-segregation state $(k=1)$, the interfacial $\mathrm{V}$ content is equivalent to around 1.7 monolayers of $\mathrm{V}$ and the $\mathrm{V}$ concentration is largest in the second metal atom layer of the carbide, while almost all interfacial $\mathrm{V}$ is contained in the interface layer in the low-segregation state $(k=0)$, as could be expected from the atomic configurations of lowest energy presented in Sec. IV A.

\section{DISCUSSION}

\section{A. Comparing experiment and prediction}

Although several measurements of V segregation to WC/Co interfaces exist in literature (e.g., Refs. 17,18,34,36, and 40), the atom probe study of Weidow et $a l^{42}$ is the only one we are aware of that reports the $\mathrm{V}$ segregation in terms of number of segregated atoms. In their study, a segregation equivalent to 1.0 and 1.1 (111) monolayers of $\mathrm{V}$ was found at two WC/Co interfaces, but also the formation of a thicker interfacial $(\mathrm{V}, \mathrm{W}) \mathrm{C}_{x}$ precipitate was reported. In the two $\mathrm{WC} / \mathrm{Co}$ interfaces with no intermediate $(\mathrm{V}, \mathrm{W}) \mathrm{C}_{x}$ precipitate, the measured amount of $\mathrm{V}$ is thus less than our prediction for $\mathrm{WC}(0001)$ at sintering conditions. It can be noted that in Ref. 42, no determination of WC boundary plane was made before the atom tomography and, furthermore, the production parameters were such that the typical faceted prism shape of WC grains bounded by $\{0001\}$ and $\{10 \overline{1} 0\}$ planes had not fully been attained. As several studies ${ }^{17,18,34,36,40}$ have shown the largest $\mathrm{V}$ segregation to the $\mathrm{WC}(0001)$ surface, it is no contradiction that atom probe measurements yield lower $\mathrm{V}$ segregation to a WC surface of undetermined and thus possibly different orientation. In principle, this issue can be solved in future experimental studies by prior determination of surface orientation.

A more complicated issue is how much experimental segregation measurements performed after cooling differ from predictions for high-temperature equilibrium. Haglund et al. ${ }^{19}$ have calculated binder phase composition profiles as a function of distance from the WC/Co interface. For normal cooling rates, their calculation suggests that binder composition is almost homogeneous until around 1400 to $1300 \mathrm{~K}$, where composition gradients start to appear. Diffusion proceeds until 1200 to $1100 \mathrm{~K}$, where composition profiles freeze in. ${ }^{19}$ For the example material, $(\mathrm{V}, \mathrm{W}) \mathrm{C}_{x}$ precipitates should have formed at these temperatures, which was also reported. ${ }^{42}$ Often, $(\mathrm{V}, \mathrm{W}) \mathrm{C}_{x}$ precipitates form in junctions between WC grains, ${ }^{37}$ where, presumably, nucleation barriers are smaller than on the flat $\mathrm{WC}(0001) / C o$ interface. However, some additional segregation of $\mathrm{V}$ seems to occur also to flat interfaces. In the study of Kawakami et al., ${ }^{17} \mathrm{~V}$ segregation was found smaller with rapid cooling especially in the $\mathrm{WC}(0001) / \mathrm{Co}$ interface (around $50 \%$ of that for normal cooling), but was still pronounced also in this case. From their HRTEM work, the number of layers in the segregation structure was 1-2 for rapid cooling, which is in agreement with our modeling, but increased to 2-4 for normal cooling. ${ }^{17}$ Their results suggest that the final structure and composition of the $\mathrm{WC}(0001) / \mathrm{Co}$ interfaces in the sintered material depend on the details of diffusion and local geometry, which complicates a direct comparison between prediction and measurement. It does, however, not invalidate our main conclusion that the $\mathrm{WC}(0001) / \mathrm{Co}$ interface is in a high-segregation state for a wide range of $\Delta \mu_{\mathrm{VC}}$.

\section{B. Influence of model assumptions}

In our present modeling, we have neglected the explicit (the nonconfigurational part) temperature dependence of the free-energy differences $\Delta \gamma^{k}$ (see Sec. IIE). Vibrations are likely to give the most important contribution to this explicit temperature dependence, and an estimate based on realistic differences in vibrational frequencies leads to a maximum inaccuracy of $\pm 0.3 \mathrm{~J} / \mathrm{m}^{2}$ for $\Delta \gamma^{k}$ (see Ref. 3). This means that we can not with full certainty determine which of the stackings $0 \leqslant k \leqslant 2$ is equilibrium for the $\mathrm{WC}(0001)$ surface at liquidphase sintering temperatures. It is possible that temperaturedependent effects would expand the $k=2$ region of the interface diagram of Fig. 4 to lower temperatures, in which case the theoretically predicted amount of segregated $\mathrm{V}$ would agree with the experimental finding in Ref. 42. It can, however, not be ruled out that instead the $k=0$ region should expand, which would mean that most of the experimentally measured interfacial $\mathrm{V}$ in Ref. 42 have segregated during the cooling phase. In any case, it is clear that in the example material, the $\mathrm{WC}(0001) / \mathrm{Co}$ interfaces should, if in equilibrium, be in 
a high-segregation state throughout solid-state sintering and within the solidus-liquidus region (see Fig. 5).

In the segregation structures, we neglected $\mathrm{C}$ vacancies. If included, they are expected to have a small stabilizing effect on the stackings $k>0$ relative to $k=0$ and to slightly lower the $\mathrm{V}$ content. The expectation is based on the fact that the $\mathrm{Clattice}$ of the cubic $(\mathrm{V}, \mathrm{W}) \mathrm{C}_{x}$ phase contains around $10 \%$ vacancies, ${ }^{46}$ whereas hexagonal WC contains essentially no $\mathrm{C}$ vacancies, and that cubic $\mathrm{WC}_{x}$ has a larger C-vacancy concentration than $\mathrm{VC}_{x}$. From calculations using CALPHAD assessments, ${ }^{21,46}$ the effect of introducing $\mathrm{C}$ vacancies in bulk $(\mathrm{V}, \mathrm{W}) \mathrm{C}$ is a decrease in Gibbs energy of around $0.04 \mathrm{eV}$ per formula unit [calculated as difference in driving force of nucleation between $(\mathrm{V}, \mathrm{W}) \mathrm{C}_{x}$ and $(\mathrm{V}, \mathrm{W}) \mathrm{C}_{x=1}$ under conditions where $(\mathrm{V}, \mathrm{W}) \mathrm{C}_{x}$ is stable] and a few atomic percent units lower $\mathrm{V}$ fraction. However, a small set of DFT calculations for $\mathrm{C}$ vacancies in the segregation structures and bulk $(\mathrm{V}, \mathrm{W}) \mathrm{C}_{x}$ shows that the $\mathrm{C}$ vacancy energies are higher (making vacancies less preferable) in the segregation structure, and thus the stabilizing effect in the interface should only be a small fraction of that for bulk $(\mathrm{V}, \mathrm{W}) \mathrm{C}_{x}$.

When fitting the CEs, we used non-spin-polarized calculations. In most of the temperature interval of interest $(1000 \mathrm{~K}<T<2000 \mathrm{~K})$, the Co binder phase is in its paramagnetic state. ${ }^{67}$ Accurately modeling the thermodynamics of Co magnetism would require detailed knowledge of the energetics of the magnetic interactions in Co. However, we expect that a comparison between the ferromagnetic and nonmagnetic states, which are easily accessible with standard DFT calculations (spin- and non-spin-polarized, respectively), provides an indication of the influence of the Co magnetic state on the relative stability of the different segregation structures. By calculating $\Delta \gamma_{0}^{k}$ for $1 \leqslant k \leqslant 4$ with $y_{\mathrm{V}}=0$ or 1 with spin- and non-spin-polarized DFT, we find the maximal absolute value of the difference in $\Delta \gamma_{0}^{k}$ between these calculations among all tested configurations to be $0.03 \mathrm{eV}$ per interfacial $\mathrm{V} / \mathrm{W}$ atom $\left(0.07 \mathrm{~J} / \mathrm{m}^{2}\right)$, whereas the mean difference is around one third of that. A check of the magnetic structure in the spin-polarized calculations reveals that, as expected, no magnetic moments develop in the bulk of the carbide, but $\mathrm{V}$ (W) atoms in the layer closest to Co obtain moments of $\sim 0.3(\sim 0.1)$ Bohr magnetons aligned antiparallel with respect to the ferromagnetically aligned moments of the Co atoms. Apparently, these small magnetic moments in the carbide interface layer have little energetic effect. Together, these results indicate that the influence of the Co magnetic state on $\Delta \gamma^{k}$ is small in comparison with, e.g., the vibrational effect. We would nevertheless like to point out that a detailed treatment of magnetic interactions would be necessary to accurately calculate an absolute value of $\gamma$.

\section{WC grain growth and $\mathrm{V}$ segregation}

In light of the calculated WC(0001)/Co interface diagram, we will finally speculate on the mechanism behind the grain growth inhibiting effect of $\mathrm{V}$. The driving force responsible for grain growth comes from the excess Gibbs energy associated with the interphase and intraphase interfaces in the WC$\mathrm{Co}$ microstructure. Although the predicted effect of $\mathrm{V}$ on the $\mathrm{WC}(0001) / \mathrm{Co}$ interface energy is significant at large V dopings, a similarly large effect can not be expected for other WC/Co interfaces as, e.g., WC(1010)/Co, where our previous calculations show a smaller effect of $\mathrm{V}^{27}$ Therefore, a reduction in driving force is not a likely explanation of the inhibiting effect. Rather, it should arise from an interference with the WC precipitation mechanism at the WC/Co interface.

Once the WC grains have attained their typical faceted shape (which can happen already in solid-state sintering for small initial grain sizes ${ }^{68}$ ), the most important growth mechanism has been argued to be defect assisted, ${ }^{69}$ but also two-dimensional (2D) nucleation has been proposed. ${ }^{70-72}$ In both mechanisms, growth proceeds by atoms from the binder attaching at surface steps of atomic height. Kawakami et al. suggested that segregation of $\mathrm{V}$ along the steps suppresses the step motion since attached $\mathrm{V}$ owing to its low solubility in WC must detach before $\mathrm{W}$ can attach. ${ }^{17}$ In our view, this explanation is feasible, but needs to be altered for the $\mathrm{WC}(0001) / \mathrm{Co}$ interface if it is covered with a film of segregated V. Under these circumstances, step motion would necessarily become more complicated. Since the atomic stacking at the interface is different than in bulk WC, several atoms (both $\mathrm{V}$ and W) ahead of the step would need to detach and W atoms subsequently refill the empty space. If instead $\mathrm{V}$ segregation were limited to interfacial steps, detachment of only single $\mathrm{V}$ atoms would be necessary for step motion. It is reasonable to assume that simultaneous detachment of several atoms occurs less frequently than detachment of single atoms, which would make growth inhibition more effective under conditions when $\mathrm{WC} / \mathrm{Co}$ interfaces are in a high-segregation state.

As Fig. 4 shows, the $\mathrm{V}$ segregation is not a continuous function of $T$ and $\Delta \mu_{\mathrm{VC}}$. Thus, one could expect that there should be a significant difference in growth rate for $\mathrm{V}$ additions corresponding to $\Delta \mu_{\mathrm{VC}}$ above and below the interfacial phase transition. For the example material, more than monolayer $\mathrm{V}$ segregation is predicted throughout its sintering. An interesting experiment would therefore be to lower the $\mathrm{V}$ addition beyond the predicted transition line to submonolayer segregation and see whether a significant increase in WC growth rate can be detected.

However, a real material contains a multitude of interfaces of various interface planes and orientations, and it is not certain that all WC surfaces contain a V-rich film even if the system is doped up to the $(\mathrm{V}, \mathrm{W}) \mathrm{C}_{x}$ solubility limit. Since the largest V segregation is found in the $\mathrm{WC}(0001) / \mathrm{Co}$ interface, ${ }^{17,18,34,36,40}$ we expect that its transition between the high- and low-segregation state occurs at the largest $\Delta \mu_{\mathrm{VC}}$ among all interfaces. For example, based on results from previous calculations, ${ }^{27}$ we expect the WC(1010)/Co interface to be in a high-segregation state only at smaller $\Delta \mu_{\mathrm{VC}}$. Thus, a decreasing $\Delta \mu_{\mathrm{VC}}$ (corresponding to larger $\mathrm{V}$ doping or lower temperature) should increase the growth inhibiting effect of $\mathrm{V}$ as pronounced segregation to more interfaces occurs. To make a complete complexion diagram for the doped WC-Co system (similar to the schematically sketched diagram of the $\mathrm{Al}_{2} \mathrm{O}_{3}-\mathrm{SiO}_{2}$ system in Ref. 7), further work is needed to map out free energies of more interfaces. Together with experimental studies at well-defined thermodynamic conditions, this would make it possible to establish a clear link between measured growth rate and predicted high-temperature equilibrium segregation. 


\section{SUMMARY AND CONCLUSIONS}

In this work, we have developed a method for calculating an equilibrium interfacial phase diagram depicting regions of stability for different interface structures as a function of temperature and chemical potential of a segregant. We use DFT for interfacial energetics, Monte Carlo simulations together with cluster expansions based on DFT results for obtaining configurational free energies, and CALPHAD-type analysis for describing the thermodynamic properties of the adjoining bulk phases.

The method is applied to the WC(0001)/Co interface in the $\mathrm{V}$-doped WC-Co system. The upper limit of the V potential, and thus also the limit of the interface diagram, corresponds to the formation of the $(\mathrm{V}, \mathrm{W}) \mathrm{C}_{x}$ phase. In this limit, the interface would be covered by $(\mathrm{V}, \mathrm{W}) \mathrm{C}_{x}$ precipitates, and the thickness and amount of $\mathrm{V}$ of these would not be determined by intensive thermodynamic variables. Owing to the large energetic effect of $\mathrm{V}$ in the WC/Co interface, there is an extended interval of $\mathrm{V}$ potential between $(\mathrm{V}, \mathrm{W}) \mathrm{C}_{x}$ precipitation and submonolayer $\mathrm{V}$ segregation, where the $\mathrm{V}$ content corresponds to slightly below two equivalent $\mathrm{V}$ monolayers. At high enough temperatures (above $\sim 1800 \mathrm{~K}$ ), a region with a $\mathrm{V}$ content of around one equivalent $\mathrm{V}$ monolayer appears.

A comparison between our prediction and atom probe data of a WC/Co interface in an example of V-doped WC-Co is made. The high-temperature equilibrium prediction for the interfacial $\mathrm{V}$ content is 1.7 equivalent $\mathrm{V}$ monolayers, whereas atom probe measurements yield $1.0-1.1$ equivalent $\mathrm{V}$ monolayers. The discrepancy could be both due to model assumptions and experimental uncertainty of interface orientation.
Finally, we discuss the relation between $\mathrm{V}$ segregation and WC grain growth inhibition. We argue that the high tendency of $\mathrm{V}$ segregation and the formation of a thin V-rich carbide film over a wide range of temperatures and chemical potentials of $\mathrm{V}$ corresponding to $\mathrm{V}$ additions below the $(\mathrm{V}, \mathrm{W}) \mathrm{C}_{x}$ solubility limit provides a consistent explanation of the experimentally established WC grain growth inhibition. Since there is a distinct transition between segregation in monolayer and submonolayer proportions, respectively, it should be experimentally possible by varying the amount of $\mathrm{V}$ addition and/or sintering temperature to obtain either monolayer or submonolayer V segregation to WC/Co interfaces during hightemperature sintering. Correspondingly, substantially different WC grain growth rates would be expected for these two cases.

In conclusion, we present an interfacial phase diagram for the WC(0001)/Co interface in the V-doped WC-Co system. The presented diagram is a first step towards a complete complexion diagram for the doped WC-Co system. Together with thermodynamic modeling of the bulk phases, the interface diagram can be used to tune sintering temperature and dopant addition to perform interfacial kinetic engineering in order to tailor the material's microstructure.

\section{ACKNOWLEDGMENTS}

Financial support from the Swedish Research Council (VR), Sandvik and Seco Tools is gratefully acknowledged. Computations have been performed on SNIC resources. We thank S. Norgren and the late B. Jansson for fruitful discussions. B. Jansson provided thermodynamic data.
${ }^{1}$ J. Luo, Crit. Rev. Solid State Mater. Sci. 32, 67 (2007).

${ }^{2}$ L. P. H. Jeurgens, Z. Wang, and E. J. Mittemeijer, Int. J. Mater. Res. 100, 1281 (2009).

${ }^{3}$ S. A. E. Johansson and G. Wahnström, Philos. Mag. Lett. 90, 599 (2010).

${ }^{4}$ M. P. Harmer, Science 332, 182 (2011).

${ }^{5}$ M. Baram, D. Chatain, and W. D. Kaplan, Science 332, 206 (2011).

${ }^{6}$ J. Luo, [J. Am. Ceram. Soc., online published (2012)].

${ }^{7}$ S. J. Dillon, M. Tang, W. C. Carter, and M. P. Harmer, Acta Mater. 55, 6208 (2007).

${ }^{8}$ S. J. Dillon, M. P. Harmer, and J. Luo, JOM 61, 40 (2009).

${ }^{9}$ M. P. Harmer, J. Am. Ceram. Soc. 93, 301 (2010).

${ }^{10}$ J. Luo and X. Shi, Appl. Phys. Lett. 92, 101901 (2008).

${ }^{11}$ X. Shi and J. Luo, Phys. Rev. B 84, 014105 (2011).

${ }^{12}$ J. Weidow, S. Norgren, and H.-O. Andrén, Int. J. Refract. Met. Hard Mater. 27, 817 (2009).

${ }^{13}$ J. Weidow, J. Zackrisson, B. Jansson, and H.-O. Andrén, Int. J. Refract. Met. Hard Mater. 27, 244 (2009).

${ }^{14}$ Z. Z. Fang, X. Wang, T. Ryu, K. S. Hwang, and H. Y. Sohn, Int. J. Refract. Met. Hard Mater. 27, 288 (2009).

${ }^{15}$ W. D. Schubert, A. Bock, and B. Lux, Int. J. Refract. Met. Hard Mater. 13, 281 (1995).

${ }^{16}$ S. Lay, J. Thibault, and S. Hamar-Thibault, Philos. Mag. 83, 1175 (2003).

${ }^{17}$ M. Kawakami, O. Terada, and K. Hayashi, J. Jpn. Soc. Powder Powder Metall. 51, 576 (2004).
${ }^{18}$ M. Kawakami, O. Terada, and K. Hayashi, in Proceedings of the 16th International Plansee Seminar, Vol. 2, edited by G. Kneringer, P. Rödhammer, and H. Wildner (Plansee Holding AG, Reutte, Tyrol, Austria, 2005), p. 653.

${ }^{19}$ S. Haglund and J. Ågren, Acta Mater. 46, 2801 (1998).

${ }^{20}$ K. Frisk, L. Dumitrescu, M. Ekroth, B. Jansson, O. Kruse, and B. Sundman, J. Phase Equilib. 22, 645 (2001).

${ }^{21}$ A. Markström, B. Sundman, and K. Frisk, J. Phase Equilib. Diff. 26, 152 (2005)

${ }^{22}$ L. Ramqvist, Int. J. Powder Metall. 1 (1965).

${ }^{23}$ M. W. Finnis, J. Phys.: Condens. Matter 8, 5811 (1996).

${ }^{24}$ S. V. Dudiy, J. Hartford, and B. I. Lundqvist, Phys. Rev. Lett. 85, 1898 (2000).

${ }^{25}$ M. Christensen, G. Wahnström, C. Allibert, and S. Lay, Phys. Rev. Lett. 94, 066105 (2005)

${ }^{26}$ M. Christensen, G. Wahnström, S. Lay, and C. H. Allibert, Acta Mater. 55, 1515 (2007).

${ }^{27}$ S. A. E. Johansson and G. Wahnström, Acta Mater. 59, 171 (2011).

${ }^{28}$ J. M. Sanchez, F. Ducastelle, and D. Gratias, Phys. A (Amsterdam) 128, 334 (1984).

${ }^{29}$ A. van de Walle and G. Ceder, J. Phase Equilib. 23, 348 (2002).

${ }^{30}$ A. van de Walle and M. Asta, Modell. Simul. Mater. Sci. Eng. 10, 521 (2002).

${ }^{31}$ A. van de Walle, M. Asta, and G. Ceder, CALPHAD: Comput. Coupling Phase Diagrams Thermochem. 26, 539 (2002). 
${ }^{32}$ A. van de Walle, CALPHAD: Comput. Coupling Phase Diagrams Thermochem. 33, 266 (2009).

${ }^{33}$ C.-S. Kim, T. R. Massa, and G. S. Rohrer, J. Am. Ceram. Soc. 91, 996 (2008).

${ }^{34}$ A. Jaroenworaluck, T. Yamamoto, Y. Ikuhara, T. Sakuma, T. Taniuchi, K. Okada, and T. Tanase, J. Mater. Res. 13, 2450 (1998).

${ }^{35}$ A. Jaroenworaluck, T. Yamamoto, Y. Ikuhara, T. Sakuma, T. Taniuchi, K. Okada, and T. Tanase, in Ceramic Material Systems With Composite Structures: Towards Optimum Interface Control and Design, Ceramic Transactions, Vol. 99, edited by N. Takeda, L. M. Sheppard, and J.-I. Kon (Amer. Ceramic Society, Westerville, Ohio, USA, 1998), p. 501.

${ }^{36}$ T. Yamamoto, Y. Ikuhara, and T. Sakuma, Sci. Technol. Adv. Mater. 1, 97 (2000).

${ }^{37}$ S. Lay, S. Hamar-Thibault, and A. Lackner, Int. J. Refract. Met. Hard Mater. 20, 61 (2002).

${ }^{38}$ S. Lay, M. Loubradou, and P. Donnadieu, Adv. Eng. Mater. 6, 811 (2004).

${ }^{39}$ S. Lay, S. Hamar-Thibault, and M. Loubradou, Interface Sci. 12, 187 (2004).

${ }^{40}$ Y. Yamanaka, T. Taniuchi, F. Shirase, T. Tanase, Y. Ikuhara, and T. Yamamoto, Mater. Sci. Forum 558-559, 993 (2007).

${ }^{41}$ T. Yamamoto, Y. Yamanaka, T. Taniuchi, F. Shirase, T. Tanase, and Y. Ikuhara, in Proceedings of the 17th International Plansee Seminar, Vol. 3, edited by L. S. Sigl, P. Rödhammer, and H. Wildner (Plansee Group, Reutte, Tyrol, Austria, 2009), p. AT5.

${ }^{42}$ J. Weidow and H.-O. Andrén, Acta Mater. 58, 3888 (2010).

${ }^{43}$ I. Sugiyama, Y. Mizumukai, T. Taniuchi, K. Okada, F. Shirase, T. Tanase, Y. Ikuhara, and T. Yamamoto, Int. J. Refract. Metals Hard Mater. 30, 185 (2012).

${ }^{44}$ S. Lay, M. Loubradou, S. A. E. Johansson, and G. Wahnström, J. Mater. Sci. 47, 1588 (2012).

${ }^{45}$ A. P. Sutton and R. W. Balluffi, Interfaces in Crystalline Materials (Oxford University Press, Oxford, 1996).

${ }^{46}$ K. Frisk and A. Markström, Int. J. Mater. Res. 99, 287 (2008).

${ }^{47}$ G. Kresse and J. Furthmüller, Phys. Rev. B 54, 11169 (1996).

${ }^{48}$ H. L. Lukas, S. G. Fries, and B. Sundman, Computational Thermodynamics-The Calphad Method (Cambridge University Press, Cambridge, United Kingdom, 2007).
${ }^{49}$ E. I. Isaev, S. I. Simak, I. A. Abrikosov, R. Ahuja, Y. K. Vekilov, M. I. Katsnelson, A. I. Lichtenstein, and B. Johansson, J. Appl. Phys. 101, 123519 (2007).

${ }^{50}$ G.-X. Qian, R. M. Martin, and D. J. Chadi, Phys. Rev. B 38, 7649 (1988).

${ }^{51}$ K. Reuter and M. Scheffler, Phys. Rev. B 65, 035406 (2001).

${ }^{52}$ M. Aldén, H. L. Skriver, S. Mirbt, and B. Johansson, Surf. Sci. 315, 157 (1994).

${ }^{53}$ S. V. Dudiy, Surf. Sci. 497, 171 (2002).

${ }^{54}$ R. Warren, J. Mater. Sci. 15, 2489 (1980).

${ }^{55}$ M. Christensen and G. Wahnström, Acta Mater. 52, 2199 (2004).

${ }^{56}$ J. P. Perdew, K. Burke, and M. Ernzerhof, Phys. Rev. Lett. 77, 3865 (1996).

${ }^{57}$ P. E. Blöchl, Phys. Rev. B 50, 17953 (1994).

${ }^{58}$ G. Kresse and D. Joubert, Phys. Rev. B 59, 1758 (1999).

${ }^{59}$ M. Methfessel and A. T. Paxton, Phys. Rev. B 40, 3616 (1989).

${ }^{60}$ A. Delanoë, M. Bacia, E. Pauty, S. Lay, and C. H. Allibert, J. Cryst. Growth 270, 219 (2004).

${ }^{61}$ M. Kawakami, O. Terada, and K. Hayashi, J. Jpn. Soc. Powder Powder Metall. 53, 166 (2006).

${ }^{62}$ V. Bounhoure, J. M. Missiaen, S. Lay, and E. Pauty, J. Am. Ceram. Soc. 92, 1396 (2009).

${ }^{63}$ J. Weidow, S. Johansson, H.-O. Andrén, and G. Wahnström, J. Am. Ceram. Soc. 94, 605 (2011).

${ }^{64}$ V. Bounhoure, S. Lay, M. Loubradou, and J. M. Missiaen, J. Mater. Sci. 43, 892 (2008).

${ }^{65}$ M. Slabanja, S. A. E. Johansson, and G. Wahnström, in Proceedings of the 17th International Plansee Seminar, Vol. 2, edited by L. S. Sigl, P. Rödhammer, and H. Wildner (Plansee Group, Reutte, Tyrol, Austria, 2009). p. HM2.

${ }^{66}$ B. Sundman, B. Jansson, and J. O. Andersson, CALPHAD: Comput. Coupling Phase Diagrams Thermochem. 9, 153 (1985).

${ }^{67}$ A. Fernández Guillermet, Z. Metallkd. 80, 549 (1989).

${ }^{68}$ Z. Fang, P. Maheshwari, X. Wang, H. Y. Sohn, A. Griffo, and R. Riley, Int. J. Refract. Met. Hard Mater. 23, 249 (2005).

${ }^{69}$ G. S. Rohrer, C. L. Rohrer, and W. W. Mullins, J. Am. Ceram. Soc. 85, 675 (2002).

${ }^{70}$ Y. J. Park, N. M. Hwang, and D. Y. Yoon, Metall. Mater. Trans. A 27, 2809 (1996).

${ }^{71}$ Y. Zhong and L. L. Shaw, Ceram. Int. 37, 3591 (2011).

${ }^{72}$ K. Mannesson, J. Jeppsson, A. Borgenstam, and J. Ågren, Acta Mater. 59, 1912 (2011). 